\title{
A Research On The Parameter Optimization And Field Test Of The Simulation Speed Regulator For The Isolated Network Of Gansu Power Grid
}

\author{
Qian Weijiang ${ }^{1, a}$, Liang Fubo ${ }^{1, a}$, Zhang Yankai, ${ }^{1, a}$, Fan Weijie ${ }^{2, b}$ \\ ${ }^{1}$ Electric Power Research Institute of Gansu Power Grid Corporation, Lanzhou 730050, China; \\ 2 Beijing power Transportation company, Beijing 102401, China. \\ aqwj_927@163.com, ${ }^{\text {b }}$ fanweijie@126.com
}

Keywords: Solitary network operation, non electromechanical oscillation mode, governor,small interference.

\begin{abstract}
In view of the problem of non electromechanical mode oscillation in the process of the operation of the $\mathrm{N}$ area network in Gansu area, the cause of the accident caused by the improper governor parameter of the main unit in the isolated network is obtained by the fault simulation and field recording. Based on the analysis of PSASP small interference analysis and PSASP-GOV oscillation mode, the hidden trouble of excitation system and speed regulation system of Gansu power network is analyzed, and the recommended parameters of the operation mode of the unit are given. Finally, the measures to improve the stability of the isolated network are given.
\end{abstract}

\section{Preface}

With the increase of the scale of the modern power grid interconnection, the oscillation of the system has become one of the most important factors which restrict the safety and stability of the network. At present, the research on the power system oscillations is mainly focused on the mechanical and electrical oscillations. With the development of the power grid, the non electromechanical oscillation mode has been paid more attention. In this paper, the problem of non electromechanical mode oscillation in the process of the operation of $\mathrm{N}$ in Gansu area is analyzed, and the cause of the accident is analyzed by means of fault simulation. On this basis, through the PSASP small interference analysis, PSASP-GOV oscillation mode analysis, the investigation of the Gansu power grid excitation system, speed control system instability. Through simulation and optimization, the parameters of the model are recommended, and the rationality of the parameters is verified by field test. In view of the non electromechanical oscillation problem in the operation of the $\mathrm{N}$ area, the measures to improve the stability of the network are given.

\section{2 break down phenomenon and reason analysis}

\subsection{Break down a phenomenon}

At 9:25 in February 8, 2015, the Gansu power grid S changed to the $\mathrm{W}$ line to the $\mathrm{C}$ phase of the A phase fault, the protection action of the three-phase tripping, and the action of the $\mathrm{W}$, $\mathrm{L}$ area of the isolated network operation. In the isolated system output accounted for $29 \%$ of the local load of $\mathrm{M}$ plant frequency adjustment process, sharp fluctuations in power unit, unit body shear pin fracture, unit trip, eventually leading to $330 \mathrm{kV} \mathrm{W,} \mathrm{l} \mathrm{variable} \mathrm{total} \mathrm{pressure} \mathrm{loss,} \mathrm{causing} \mathrm{a} \mathrm{greater} \mathrm{impact} \mathrm{on}$ the local production and living.

\subsection{Break down reason analysis}

Using psasp6.29 to simulate the fault simulation of the power network, the power grid operation mode is used to model the power grid.M power plant unit governor PID, $\mathrm{Ki}=6, \mathrm{Kd}=1$, output $70 \mathrm{MW}$, simulation $330000 \mathrm{~V} \mathrm{~S}$ to the W M Kp=8 power plant unit frequency, power curve as shown below: 


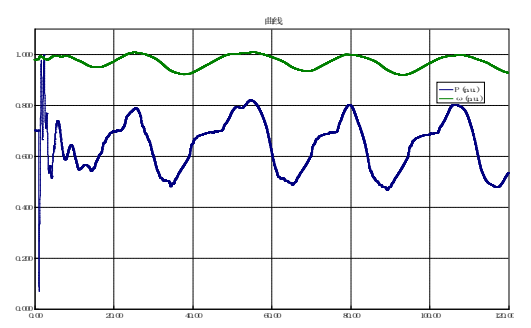

Fig. 1 the frequency and power of the $M$ power plant unit

From the simulation results, the $\mathrm{M}$ PID $\mathrm{Kp}=8, \mathrm{Ki}=6, \mathrm{Kd}=1$ and, the frequency and power oscillation of the system, the frequency of the $\mathrm{M}$ power plant is within the range of $47.35-51.85 \mathrm{~Hz}$, the power fluctuation frequency is $0.04 \mathrm{~Hz}$, and the frequency of the $\mathrm{N}$ is unstable.M power plant unit fault recording frequency, power curve as shown below:

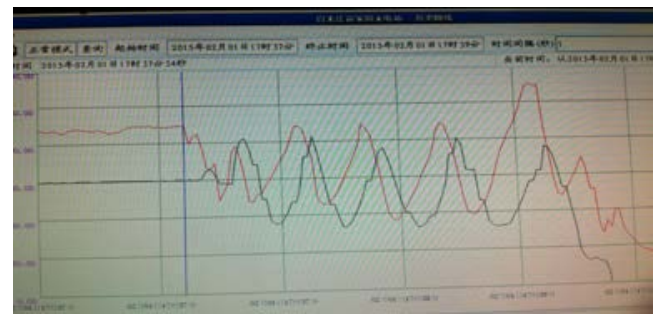

Figure $2 \mathrm{M}$ power plant unit fault recorded frequency, power curve diagram

It can be seen that the fault of the $\mathrm{M}$ power plant unit is basically the same as the simulated waveform.To optimize the parameters of the governor, in the single mode, the adjustment of PID network parameters: $\mathrm{Kp}=2, \mathrm{Ki}=0.3, \mathrm{Kd}=0.8 \mathrm{~s}$, and PID parameters $\mathrm{Ki}=6, \mathrm{Kd}=1, \mathrm{Kp}=8$, and so on:

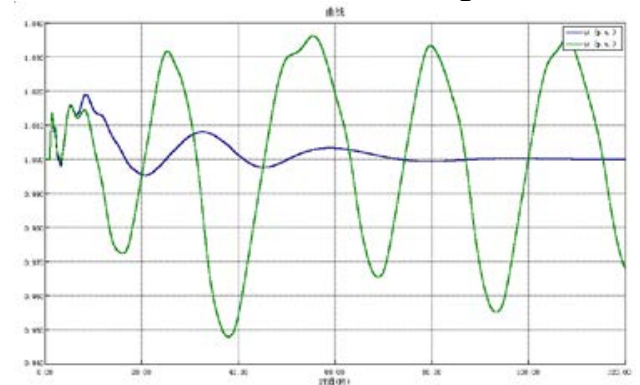

Fig. 3 the power curve of the M power plant unit under the condition of the setting of the isolated network parameters

The simulation results show that the governor of the M power plant can maintain the stability of the unit under the condition of the isolated network. It can be seen that the instability of the M power plant unit governor parameter tuning is not reasonable.

\section{Gansu power grid stability mode scanning}

The stability of the control system of the Gansu power grid is calculated and the scanning is carried out, and the attention of the non electromechanical oscillation mode is enhanced. Using psasp6.29 to scan the whole network of Gansu.

\subsection{Calculating conditions}

(1) choose the normal operation mode of the summer to carry out small interference and stability calculation of the whole network.

(2) the oscillation frequency ranges from 0 to $3.0 \mathrm{~Hz}$.

(3) oscillation modes of the strength of the judging conditions are: negative damping: zeta\% (damping ratio) <; weak damping, and zeta\%<2; weak damping: $2<$ zeta $\%<3$. Medium: $3<\%<5$ damping.

\subsection{Eigenvalue calculation results}

Gansu power grid system does not appear to be less than $2 \%$ of the weak damped oscillation mode, but there is a moderate damped oscillation mode. 
Table 1 The moderate damped oscillation mode

\begin{tabular}{ccccc}
\hline real & imag & frequency $(\mathrm{Hz})$ & Damping ratio (\%) & Electromechanical circuit correlation ratio \\
\hline-0.164239 & $\begin{array}{c}4.12333 \\
3\end{array}$ & 0.656249 & 3.98 & 7.21173 \\
\hline
\end{tabular}

\section{3 oscillation mode analysis}

The characteristic value of the oscillation mode is $-0.164239+\mathrm{j} 4.123333$, the oscillation frequency is $0.656249 \mathrm{~Hz}$, the damping ratio is $3.98 \%$, and the mechanical and electrical circuit is 7.21173 .The oscillation mode is strongly related to the G2 of B, B, B, G3 and G1, and the correlation factors are $0.125554,0.137006$ and 0.138488 respectively.

Table2 The oscillation mode of the G2 of B, B, B, G3 and G1

\begin{tabular}{cccc}
\hline bus name & real & imag & Related factors \\
\hline Gan B Power plant G2 & -0.308561 & -0.250004 & 0.138488 \\
\hline Gan B Power plant G1 & -0.306996 & -0.248754 & 0.137006 \\
\hline Gan B Power plant G3 & -0.294553 & -0.238929 & 0.125554 \\
\hline Gan Q Power plant G1 & -0.300253 & -0.229978 & 0.030137 \\
\hline Gan Q Power plant G2 & -0.300253 & -0.229978 & 0.030137 \\
\hline Gan Q Power plant G3 & -0.285914 & -0.231037 & 0.028392 \\
\hline Gan M Power plant G1 & -0.059287 & -0.043133 & 0.003784 \\
\hline Gan M Power plant G3 & -0.053945 & -0.039236 & 0.003052 \\
\hline
\end{tabular}

\subsection{GOV mode analysis}

The PSASP-GOV module analysis of the small interfering operation is carried out, and the vibration mode of the speed regulator is analyzed. The correlation factor is 0.0001 , and the analysis results are as follows:

Table3 The PSASP-GOV module analysis of the small interfering operation

\begin{tabular}{cccccc}
\hline Real & Imag & frequency(Hz) & $\begin{array}{c}\text { Damping ratio } \\
(\%)\end{array}$ & $\begin{array}{c}\text { Electromechanical } \\
\text { circuit correlation } \\
\text { ratio }\end{array}$ & \\
\hline-0.731243 & 6.30256 & 1.00308 & 11.525 & 2.03104 & \\
\hline Serial number & Bus name & real & imag & Related factors & GOV type \\
\hline 1 & $\begin{array}{c}\text { MPower } \\
\text { plantG1 }\end{array}$ & 0.001162 & -0.003489 & 0.000525 & 4 type -16 \\
\hline 2 & $\begin{array}{c}\text { M Power plant } \\
\text { G3 }\end{array}$ & 0.004342 & -0.002039 & 0.000253 & 4 type -12 \\
\hline Real & Imag & frequency(Hz) & $\begin{array}{c}\text { Damping ratio } \\
(\%)\end{array}$ & $\begin{array}{c}\text { Electromechanical } \\
\text { circuit correlation } \\
\text { ratio }\end{array}$ & \\
\hline-0.760236 & 6.34432 & 1.00973 & 11.8978 & 2.02656 & \\
\hline Serial number & Bus name & Real & Imag & Related factors & GOV type \\
\hline 1 & M Power plant & 0.000959 & -0.003204 & 0.000577 & 4 type -16 \\
\hline 2 & M Power plant & 0.003898 & -0.001926 & 0.000278 & 4 type -12 \\
\hline
\end{tabular}

Through the gov model analysis, we can see that the tone of Gansu Province tube range units and gov mode related respectively m power plant G1, m power plant G3.

\section{Test verification of the isolated network parameters of the unit}

For the situation that the governor is unable to adapt to the operation of the network, the operating mode is set up in the $\mathrm{M}$ power plant unit, and the parameters of the network are automatically entered after the frequency of the 0.3 - plus or minus.

\section{1 simulation optimization}

M power plant: $\mathrm{Kp}=2, \mathrm{Ki}=0.3,0.8 \mathrm{~s}=\mathrm{Kd}$, use this parameter to simulate the power oscillation of the unit under the condition of the isolated network parameters. The simulation analysis is based on the data source of 2015 winter big data packets. Purple curve PID parameters: 2, 0.5, 1, and dark green curve of PID parameters: 2, 0.4, 0.8, red curve PID parameters: 2, 0.24, 0.8, shallow blue curve PID parameters: 2, 0.3, 0.8), as shown in Figure 4: 


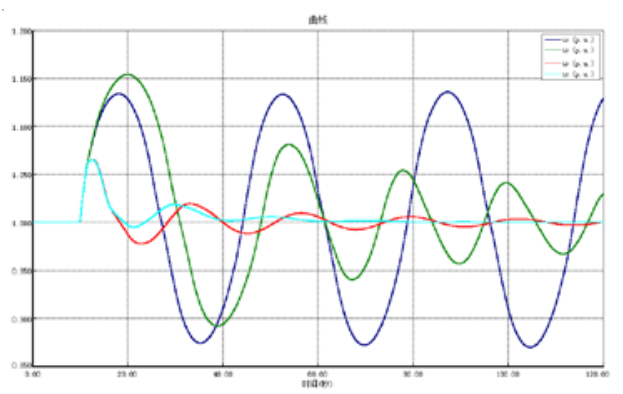

Fig. 4 the power curve of the M power plant unit under the condition of the setting of the isolated network parameters

The simulation results show that the governor of the $\mathrm{M}$ power plant can maintain the stability of the unit under the condition of the isolated network.

\section{2 measurement verification}

In order to verify the rationality of the isolated network parameters, in February 13, 2015, Gansu Province, province, in the field of the power plant to carry out the remote load rejection test, simulation of the isolated network operation mode, the speed of the governor in the mode of action.

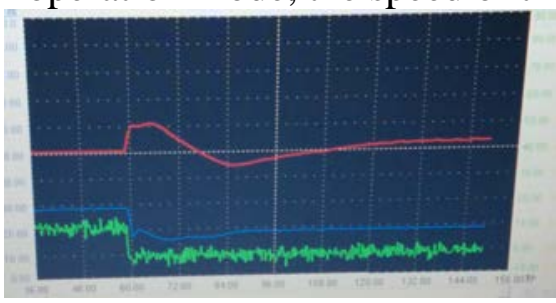

Fig. 5 power curve of the $\mathrm{M}$ power plant in the condition of the load shedding in the distance

The test results show that the speed regulator can enter into the network mode and play a regulatory role in the condition of the operation, and maintain the stability of the unit.

\section{Summary}

The governor can maintain the stable operation of the system by the size of the system. This paper analyzes the non electromechanical mode oscillation in the process of the operation of the N network in Gansu. Through simulation optimization, the parameters of the isolated network are optimized, and the parameters are verified by the field test. And on this basis, the investigation of the Gansu power grid excitation system, speed control system instability. This work is to carry out verification of the whole network speed control unit, excitation system model, parameters and functional operation situation, promote the measurement and modeling of the turbine governor, governor parameters optimization and PSS parameters and to enhance the operation stability of Gansu Power Grid to lay a good foundation.

\section{References}

[1] Wang Wei-sheng. A Practical Method of Determining Power System Small-disturbance Voltage Stability Limits[J] . Electric Power, 1998, (7): 38-40.

[2] Zhang Fang, FANG Da-zhong, CHEN Jia-rong, etal. Study on two-stage control Unified Power Flow Controller to damp tie-line low frequency oscillation[J]. Electric Power, 2006, (11): 27-32.

[3] Wang Tie-qiang, HE Ren-mu, XU Dong-jie, etal. The Validity Study of Prony Analysis for Low Frequency Oscillation in Power System[J] . Electric Power, 2001, (11): 38-41.

[4] H.D.Chiang, R.JeanJumeau. A More Efficient Formulation for Computation of the Maximum Loading Pointsin Electric Power Systems. IEEE Transactionson Power Systems, 1995, 10(2): 635-646. 
[5] C.A.Canzares, F.L.Alvarado, C.L.DeMarcoetal. Point of Collapse Methods Applied to AC/DC Power Systems. IEEE Transactionson Power Systems, 1992, 7(2): 673-683.

[6] H.D.Chiang, A.J.Flueck, K.S.Shahetal, etal. A Practical Tool for Tracing Power System Steady-state Stationary Behavior Dueto Loadand Generation Variations. IEEE Transactionson Power Systems, 1995, 10(2): 623-634.

[7] Zhang Hong-guang, ZHANGLi-zi, CHENShu-yong, etal. Influence of large scale wind farms on power system small signal stability and damping characteristic $[\mathrm{J}]$.Power System Technology, 2007, 31(13): 75-80.

[8] Yu Zhihong, LI Fang, SUN Lu, etal. An Enhanced Algorithm of Online Small Signal Stability Control Strategy Generation etal. Proceedings of the CSEE, 2014, 34(34) : 6191-6198.

[9] Zhou Ming, YUAN Bo, ZHANG Xiaoping, etal. Stochastic Small Signal Stability Analysis of Wind Power integrated Power Systems Based on Stochastic Differential Equations. Proceedings of the CSEE. 2014, 34(10): 1575-1582.

[10] Li Peijie, WEI Hua, BAI Xiaoqing. Small signal Stability Constrained Optimal Power Flow Based on NLSDP. Proceeding of the CSEE, 2013, 33(7): 69-76.

[11] Tang Zhengmao, MA Shihu, XIE De. Optimization of Hydro-turbine Governor Parameters Based on Parallel Genetic Algorithm With Exterior Archive Method. Proceeding of the CSEE, 2012, 32(28): 90-96. 